\title{
O segredo e a razão de estado: as ameaças da realpolitik para a democracia ocidental
}

The secret and the state reason: the threats of realpolitik to western democracy

Daniel Chaves de Brito ${ }^{1}$

1 Professor Titular da Faculdade de Ciências Sociais, Universidade Federal do Pará. E-mail: dnlbritodc02@gmail.com

RESUMO: O objetivo deste trabalho é fazer um percurso por autores que expuseram como surgem e a quem servem os expedientes do segredo de estado, a realpolitik. Tenta-se localizar a relação entre razão de Estado e segredo; em seguida, a partir de uma leitura de Nicolau Maquiavel, localiza-se os fundamentos desse instrumento político; prossegue-se analisando as obras políticas de Max Weber e Carl Schmitt, e por fim, baseando-se numa literatura sobre vazamento de informações, indica-se como a democracia ocidental tem sido ameaçada ao longo de muitos séculos pela persistência de instrumentos totalitários a assombrar a liberdade dos homens.

Palavras-chave: Segredo. Razão de Estado. Democracia.

ABSTRACT: The objective this work is to make a journey through authors who have exposed how the secrets of state, the realpolitik, appear and to whom they serve. We begin by trying to locate the relation between state reason and secret; then, from a reading by Niccolo Machiavelli, we trace the foundations of this political instrument; we continue analyzing the political works of Max Weber and Carl Schmitt, and finally, based on a literature on information leakage, it is pointed out how Western democracy has been threatened for many centuries by the persistence of totalitarian instruments to haunt the freedom of men.

Keywords: Secret. Reason of State. Democracy.

Sumário: Introdução - 1 A Razão de Estado como Construção de uma Narrativa Própria para a Política - 2 Weber, Schmitt e o Extremo da Política - 3 O Segredo de Estado e a Ameaça à Democracia - Considerações Finais Referências

\section{INTRODUÇÃO}

A relação entre segredo e poder certamente é imemorial. O segredo, diz Simmel (1996, p. 462) "which is effective through negative or positive means of concealment - is one of the greatest accomplishments of humanity". No contexto religioso, sobretudo na tradição judaico-cristã, o segredo é revestido de importância fundamental. No Eclesiastes $(10,20)$, por exemplo, está escrito: "Nem em pensamento fales mal do rei, nem critiques o poderoso no segredo do teu quarto; pois as aves do céu levarão tua voz, e alguém com asas vai espalhar o que disseste".

Essa passagem remete-nos diretamente ao tão citado discurso do senador americano Frank Church (pronunciado em 1975) ${ }^{1}$, que se refere à capacidade tecnológica de monitorar as comunicações entre os cidadãos americanos - e hoje estende-se esse alcance aos cidadãos do mundo - na mão do governo, pondo fim a qualquer tipo de privacidade. Em seu discurso, Frank Church conclui que "não haveria onde se

1 Um trecho deste discurso encontra-se em Greenwald (2014, p. 02). 
esconder". Isso posto, não há como não concordar com a sentença de Canetti (1995, p. 290), para quem “o segredo encontra-se no mais recôndito cerne do poder"'.

Diante isso, uma questão impõe-se de imediato: se o regime democrático é vestido com o manto da transparência, por que razão, nos séculos posteriores ao fim do absolutismo, que se apoiava na ideia de razão de Estado, cujo corolário era o segredo, a democracia não foi suficientemente capaz de impedir que sucessivos governos se utilizassem desses instrumentos como forma de justificar suas ações? E quais os riscos que a persistência desses dispositivos representa para a democracia e o Estado de direito?

Poder-se-ia estender a lista de perguntas que vem a lume quando constatamos o quanto governos democráticos, com a ajuda da tecnologia, deixam de respeitar o Estado de direito e, em nome da "segurança", invadem a privacidade de cidadãos ao redor do planeta, pondo em risco suas liberdades. Nesse sentido, o objetivo deste trabalho é fazer um percurso por autores que, enfrentando a realidade da política - a política como ela é -, tentaram expor como surgem, a quem servem e como servem aos governantes os expedientes do segredo, em nome da razão de Estado e, no limite, da mentira.

Iniciamos por tentar localizar a relação entre razão de Estado e segredo no alvorecer da democracia; em seguida, a partir de uma leitura de Nicolau Maquiavel, tenta-se encontrar os fundamentos da existência desse instrumento político; prossegue-se fazendo uma busca nas obras políticas de Max Weber, para mostrar a persistência desses dispositivos na ação política; continua-se por algumas obras de Carl Schmitt, que tenta mostrar como esses recursos extremos de poder político põem em dúvida princípios elementares da democracia liberal; por fim, com base numa literatura sobre vazamento de informações, indica-se como a democracia ocidental tem convivido com mecanismos de poder que ao longo de muitos séculos têm persistido renitentemente em assombrar a liberdade dos homens.

\section{A RAZÃO DE ESTADO COMO CONSTRUÇÃO DE UMA NARRATIVA PRÓPRIA PARA A POLÍTICA}

A discussão sobre o tema do segredo e da razão de Estado está presente sub-repticiamente na literatura sobre teoria política. O termo "razão de Estado", que é o "espírito" que conduz as evocações do pensamento de Nicolau Maquiavel (CURZIO, 2004), sobretudo na obra O príncipe, não consta, porém, nessa literatura. Mas a literatura sobre a formação do Estado moderno deixa evidente que esse autor, com suas lições ao príncipe, fez a passagem do Estado governado pelo princípio da "razão eclesiástica" para o Estado governado pelo princípio da razão de Estado.

Nesse passo, Maquiavel estabelece aquela que viria a ser uma das suas maiores contribuições para o pensamento político, a própria definição de Estado. Muito embora essa noção remonte à antiguidade clássica, aqui ela ganha um sentido preciso, um poder político centralizado atuando soberanamente em um determinado território. Certamente é na ideia de soberania que se vai aninhar a ideia de razão de Estado, pois o Estado é uma instituição com interesses próprios, exclusivos e independentes, com fins voltados para a aquisição, a conservação e o engrandecimento do poder, valendo-se para isso de qualquer meio que esteja ao seu alcance.

Assim, os interesses soberanos do Estado prevalecem mesmo que venham a entrar em conflito com preceitos éticos e morais. Assim compreendida, "la razón de Estado es, en ese sentido, una rąón instrumental e calculadora sin compromiso con los ideales morales o sociales de justicia o bien común y basada en la supremacía de las razones del poder sobre el poder de las razones, sagradas os profanas" (FERNÁNDEZ RAMOS, 2012, p. 311). 
O triunfo da ideia de razão de Estado, segundo Viroli (1992, p. 238), provocou inicialmente uma radical transformação na linguagem da política. Para ele, "the language of politics as civil philosophy gave way gradually to the conception of politics as reason of state". Não obstante, essa concepção provocou intenso debate entre os escritores da época, o que desencadeou uma forte resistência, agora já não somente ao uso do termo, mas intensamente à art of the state, provocando, assim, uma nova onda de ideias expostas em obras conhecidas como advice-for-prince, segundo Viroli (1992), ou como mirrors for princes, na acepção de Quentin Skinner (1996).

Em ambos os autores, nota-se que a posição de Maquiavel se tornou o impulso para uma discussão sobre a arte de governar, recrudescendo a disputa dentro da própria doutrina do humanismo então vigente ${ }^{2}$. Como pode-se observar, e é o que fica evidente entre os intérpretes de O príncipe, Maquiavel introduz uma nova acepção na ideia de virtude, assentando-a no desígnio da ambivalência, o que faz esse termo ser o que é até nossos dias.

A imagem ideal que deveria refletir-se no mirror of prince seria a de um governante que, em linhas gerais, cultivasse a prudência, a temperança, a justiça e a força de espírito e os valores cívicos. Assim, "the pursuit of virtue is, for the prince, the best way to attain happiness" (VIROLI, 1992, p. 240). E esse seria o caminho para atingir o mais elevado grau de honra, glória e fama, Skinner (1996, p. 139), assinala que muitos humanistas "costumavam considerar o príncipe alguém capaz de atingir uma virtus quase insuperável”.

Com o cultivo dessas qualidades, o príncipe poderia reduzir e controlar o poder da fortuna: "um príncipe que tenha virtus também será o que tem as melhores qualidades para conquistar o apoio da caprichosa deusa na condução dos negócios" (SKINNER, 1996, p. 141). Em relação à noção de virtù, Skinner faz um esforço de análise para apresentar, em pormenores, a conotação que vai prevalecer a partir do pensamento de Maquiavel. Antes de tudo, enfatiza que

Maquiavel considera, porém, que essa é uma perspectiva ingênua, pela qual se esquece em que medida a manutenção de um governo bem-sucedido depende de uma disposição inabalável a suprir as artes da persuasão mediante o recurso à força militar efetiva (SKINNER, 1996, p. 150).

A referência vai para o capítulo XIV da obra O príncipe, onde lê-se: "Um príncipe deve, pois, não deixar nunca de se preocupar com a arte da guerra e praticá-la na paz ainda mais mesmo que na guerra" (MAQUIAVEL, 1983, p. 59). O ponto culminante nessa perspectiva maquiaveliana é a introdução da violência e da força bruta, agora de forma explícita, como instrumento da política, ao lado da persuasão.

Num segundo momento de sua interpretação da posição de Maquiavel sobre o aconselhamento do príncipe, Skinner destaca a mais veemente crítica de Maquiavel às virtudes convencionalmente ensinadas por pensadores que lhe antecederam. Jogando no campo da realidade política, o autor condena a perspectiva imaginativa dos pensadores que se baseiam nas virtudes e na moral cristã. E afirma: "muita gente imaginou repúblicas e principado que nunca se viram nem jamais foram reconhecidos como verdadeiros" (MAQUIAVEL, 1983, p. 63).

No que diz respeito ao comportamento do príncipe, diante das exigências de se manter uma conquista, a ideia de bondade foge completamente do seu tratamento convencional, do ideal e até mesmo de uma certa "utopia". Para o autor de O príncipe, os parâmetros que balizam a ideia de bondade e de maldade devem ser extraídos da necessidade. Para Maquiavel (1983, p. 63), "é necessário a um príncipe, para se

2 Para uma compreensão do humanismo na formação do pensamento político moderno, ver Skinner (1996). 
manter, que aprenda a poder ser mal e se valha ou deixe de valer-se disso segundo a necessidade". Essa colocação parece traduzir-se numa fórmula que Skinner (1996, p. 152) encontrou em Hamlet: às vezes, é necessário "ser cruel apenas para ser bondoso".

Analisando os capítulos que tratam do comportamento do príncipe ante a necessidade de manter o Estado, sobretudo no que diz respeito às noções de ódio e amor, prudência, astúcia e vício, o que salta aos olhos é a indicação de que o verdadeiro talento de um governante é a capacidade de dissimulação. A mentira e o embuste são instrumentos preciosos da política, pois “tão simples são os homens, e obedecem tanto às necessidades presentes, que aquele que engana sempre encontrará quem se deixe enganar"; com isso "um príncipe não precisa possuir todas as qualidades (virtudes), bastando que aparente possuí-las; "é que os homens, em geral julgam mais pelos olhos do que pelas mãos, pois todos podem ver, mas poucos são os que sabem sentir" (MAQUIAVEL, 1983, p. 74-75).

As lições de Maquiavel, assim como não apresentam de forma explicita a noção de razão de Estado, tampouco apresentam a importância de administrar informações em segredo. Mas principalmente os capítulos 18 e 19 mostram que um governante pode sofrer inúmeras ameaças de ruína se não der a devida importância à traição. Diz Maquiavel (1983, p. 77): “um príncipe deve ter duas razões de receios: uma de ordem interna, por parte de seus súditos, outra de ordem externa, por parte dos poderosos de fora".

O sucesso para o controle das conspirações secretas está em juntar num mesmo homem a reserva e a dissimulação. Por isso "todos veem o que tu pareces, mas poucos o que és realmente, e estes poucos não têm a audácia de contrariar a opinião dos que têm por si a majestade do Estado" (MAQUIAVEL, 1983, p. 75). Seguindo esse raciocínio, Viroli (1992, p. 252) assinala: "the language of the state had so far been almost exclusively a sort of confidential language used in memoranda and letters, or whispered in de prince's ears, or discussed in the secret the prince's room”.

Como já está consagrado na história política do Ocidente, o pensamento de Maquiavel nunca foi pacífico e, a noção de razão de Estado tem contribuído significativamente para esse embate. Não é difícil identificar analistas que viram nessas lições políticas uma tentativa de emancipar a política da ética ${ }^{3}$ e de circunscrevê-la à senda da maldade. Assim

La razón de Estado se halla vinculada al mal. Para muchos la politica en general también lo está. Parece que ambas supondrían transgresión de valores que nos son queridos y rupturas con nuestras ideas sobre la moral y la justicia. Sin embargo, siguen con nosotros y desafían todos los intentos por domarlas en el horizonte teórico o en los ámbitos practicos" (ÁGUILA TEJERINA, 2000, p. 31).

Leo Strauss, acompanhando essa tese, escreveu uma das obras mais importantes sobre Maquiavel, que inicia conjecturando que ninguém ficará chocado "if we profess ourselves inclined to the old-fashioned and simple opinion to which Machiavelli was a teacher of evil". (STRAUSS, 1958, p. 9). Na sequência do texto, Strauss expõe algumas das principais lições nas quais Maquiavel demonstra o uso da violência como instrumento da política e conclui dizendo: "if it is true that only an evil man will stoop to teach maxims of public and private gangsterism, we are forced to say that Machiavelli was an evil man” (STRAUSS, 1958, p. 9).

A crítica mais contundente de Strauss direciona-se para a ideia difundida na obra maquiaveliana de

\footnotetext{
${ }^{3}$ Um dos autores mais importantes que insiste nessa tese é Croce (1994), em seu livro Ética e política. No entanto, há uma série de pensadores que crítica de diversas formas essa leitura. Ao longo do texto, serão expostos alguns pontos dessa controvérsia.
} 
que o paganismo leva ao triunfo do mundo e o cristianismo, a sua fraqueza. Nesse contexto, Maquiavel segue a indicação de que a política tem razões próprias e manipula os instrumentos necessários para alcançar objetivos determinados. Maquiavel não hesita em afirmar que boas armas são necessárias e constituem a condição suficiente para boas leis.

Assim, a política romana antiga seria o seu modelo preferencial, pois ela ainda representa uma supremacia da autoridade política diante da autoridade religiosa cristã. Strauss, então, concentra sua crítica na falta de compreensão da conjuntura política por Maquiavel, que analisava os acontecimentos históricos e políticos restritos à península italiana e generalizava sua compreensão para o mundo político como um todo. Com isso, voltando-se para a retomada dos tempos gloriosos de Roma, Maquiavel exalta a autoridade que faz uso da força para proteger o Estado e elogia o paganismo, que estaria livre de qualquer barreira moral religiosa na tarefa de conquistar o Estado.

Strauss, em todo o seu trabalho, faz um esforço interpretativo para manter a tese central de que Maquiavel, como pensador político, valeu-se de vários ardis de caráter duvidoso para chamar a atenção para suas lições. Assim, de um modo muito particular, Strauss destaca a sedução que os ensinamentos maquiavelianos exercem sobre seus leitores, guiando-os em direção de princípios dogmáticos. Diz Strauss (1958, p. 12): "They do not see the evil character of his thought because they are the heirs of the Machiavellian tradition; because they, or the forgotten teachers of their teachers, have been corrupted by Machiavelli". O objetivo fundamental de Strauss é, sem dúvida, levantar uma série de questões sobre o caráter do pensamento maquiaveliano.

Uma avaliação traz à tona o principal percurso que segue Strauss nessa polêmica: seria provar os estragos que a obra de Maquiavel havia causado para o entendimento tanto da religião quanto da política na era moderna. Assim, desde o início de suas reflexões, Strauss (1958, p. 11-12) deixa bem explícito: "we do not hesitate to assert, as very many have asserted before us, and we shall later on try to prove, that Machiavelli's teaching is imoral and irreligious.

O antimaquiavelismo de Strauss - destilado na lapidar afirmação de ser Maquiavel "um mestre do mal” - é apenas uma voz entre inúmeras que surgiram desde seu aparecimento ${ }^{4}$. Berlin (1980), em um livro intitulado Against the current: essays in the history of ideas, esceve um capítulo bem sugestivo, denominado "The originality of Machiavelli" (A originalidade de Maquiavel).

Berlin não se exime do tema central, já aventado por Strauss, apenas busca uma interpretação diferente, não sem antes mostrar uma série de interpretações injustas e equivocadas das obras de Maquiavel. Seria então injusto atribuir a esse pensador ter operado uma distinção entre moral e valores políticos ou ter provocado a emancipação da política ante a ética e a religião.

O que ele propôs "is something that cuts deeper still - a differentiation between two incompatible ideals of life, and therefore two moralities" (BERLIN, 1980, p. 45), de um lado, a moralidade do mundo pagão, com uma série de valores, como o cultivo da coragem, da força, da ordem, da astúcia e do poder; do outro lado, a moralidade cristã, com ideais de caridade, de misericórdia, de sacrifício, de perdão aos inimigos.

A restauração dos vigorosos valores do tempo de Roma pré-cristianismo seria essa a perspectiva por trás das obras de Maquiavel. De acordo com Berlin (1980, p. 45), "these seem to Machiavelli the best hours

\footnotetext{
4 "Así pues, el antimaquiavelismo será la realidad, teórica por lo menos, que permita darle forma y contenido a la razón de Estado, permitiendo el crecimiento de la filosofía política barroca, pues ésta se levantará, más que como enemiga de la Reforma, como gran enemiga del maquiavelismo" (VELÁSQUEZ DELGADO, 2013, p. 225).
} 
of mankind and, Renaissance humanist that he is, he wishes to restore them". Quem abraçasse um objetivo como esse deveria estar convicto de sua escolha, pois “one can save one's soul, or can found or maintain or serve a great and glorious state; bus not always both once" (BERLIN, 1980, p. 50). E o secretário florentino, ao afirmar que "he loved his native city more than his own soul", revelou, segundo Berlin (1980, p. 54), sua crença moral.

No âmbito da política, é importante reconhecer uma sistemática necessidade do uso da astúcia e da força pelos governantes, o que afasta qualquer tipo de orientação moral diferente. Por isso, diz Berlin (1980, p. 55), "Machiavelli's values are not Christian, but they are moral values". Em outro momento novamente assinala: "Machiavelli's values may be erroneous, dangerous, odious; but he is in earnest. He is not a cynical". (BERLIN, 1980, p. 62).

Após uma avaliação minuciosa, Berlin anuncia que "the great originality and the tragic implications of Machiavelli's theses seem to me reside in their relation to a Christian civilization" (BERLIN, 1980, p. 63). O trágico encontra-se na existência de um descompasso de tempo entre o triunfo do cristianismo e as concepções políticas modeladas por ideais pagãos, que forçaram o homem a fazer escolhas conscientes, mas dolorosas entre dois mundos. Desde então, o homem, afirma Berlin (1980, p. 63), "have lived in both, and fought and died to preserve them against each other. Machiavelli has opted for one of them, and he is prepared to commit crimes for its sake". Finaliza Berlin: "It is Machiavelli's great merit that he does not deny this".

As lições de Maquiavel, certamente, extravasam ambivalências interpretativas. Suas obras lidam com os limites da ética na ação política, e a ideia de virtù pode bem ser o elemento carregado de ambivalências. Pode-se depreender isso de uma leitura, que supõe que os atos políticos, mais que quaisquer outros atos, estão sempre sob o olhar e o julgamento de todos.

Nesse ponto, Bignotto (1992, p. 116) sugere que Maquiavel opera com dois tipos de ideia de virtù: de um lado, está a virtù do tirano, "pura técnica do uso da força", o qual é obrigado, para reproduzir seu poder, a lançar mão da violência; de outro, está o homem político, que "descobre que sua virtù não pode deixar inteiramente de lado o uso da violência", mesmo que seu objetivo seja a busca da glória. Com base nessa interpretação o autor afirma que

interessante é que, referindo-se ao abuso da violência, Maquiavel não diz que os tiranos são meras deformações do jogo político. Se eles não podem jogá-lo até o fim, são capazes de galgar pelo menos uma de suas etapas: o poder. O exercício da crueldade não é, pois, inteiramente alheio à política; ele coloca a nu uma de suas dimensões (BIGNOTTO, 1992, p. 116).

Por isso, Bignotto (1992, p. 116), diz que somos impedidos de "considerar a ruptura da ética com a política um dos pilares inequívocos sobre o qual se ergue a filosofia moderna".

\section{WEBER, SCHMITT E O EXTREMO DA POLÍTICA}

O pensamento político, sobretudo a teoria política moderna, passa obrigatoriamente pelo caminho aberto por Maquiavel. As reflexões tanto no âmbito da filosofia e da sociologia política, quanto na dimensão do agir político levado pelos meandros do realismo prático, mantêm na lembrança o "espírito" intelectual de Maquiavel. Nesse sentido, nenhum autor, do moderno pensamento político, carrega tão veementemente a carga de "herdeiro" do pensamento maquiaveliano do que Max Weber.

E nenhuma de suas obras sustenta esse caráter mais diretamente do que a sua famosa conferência 
"A política como vocação" (WEBER, 1982). As nuances mais significativas das questões referentes à análise da razãa de Estado e de seu elemento fundamental, o segredo - entendidos como fatores do cálculo racional na política -, como que se enlaçam ao universo dos ensinamentos de Maquiavel.

É no âmbito da realpolitik alemã que se vão circunscrever os objetivos e as preocupações de Weber com a política e é nesse contexto que a obra de Maquiavel ganha importância. Segundo Mayer (1998, p. 16), “Bismarck's example made Max Weber understand the lesson of Machiavelli's Principe". Assim, em pelo menos três trabalhos, A política como vocação (WEBER, 1982, p. 97-153), Parlamento e governo na Alemanha reconstruída (WEBER, 2014, p. 167-342) e O Estado-nação e a política econômica (WEBER, 2014, p. 3-36), encontra-se uma preocupação comum: são obras que poderiam serem colocadas entre aquelas denominadas advice-for-prince ou mirrors for princes.

Ao analisar as noções de Estado, força e poder no conjunto da obra de Weber, Dreifuss (1993, p. 10) assinala: "Weber é um intelectual por pendor e formação, mas um conselheiro do príncipe por vocação". Ao que parece, Weber esmerou-se no conhecimento dessa literatura ${ }^{5}$. O universo histórico e político no qual se insere $O$ príncipe de Maquiavel dispõe sobre uma arte de governar, que aos poucos vai deixando de ser autocrática, abrindo espaço para o posicionamento de uma burocracia cada vez mais técnica a serviço do príncipe (WEBER, 1982, p. 110).

A importância dessa estrutura é, para o pensamento weberiano, o que marca a modernidade em relação ao passado, pois é a ela que se incorpora o processo de racionalização crescente das esferas da vida social. A luta pelo poder sai do campo pessoal e impõe-se como uma luta entre a burocracia e a política, aqui a política encarnada nos parlamentos modernos. A importância dessa questão aparece claramente em "Parlamento e governo na Alemanha reconstruída", quando Weber (2014, p. 22) afirma: "Num Estado moderno, necessária e inevitavelmente a burocracia realmente governa, pois o poder não é exercido por discursos parlamentares nem por proclamações monárquicas, mas por meio da rotina da administração".

A luta pelo poder, ou o que seria a política em ação, insere-se em um universo próprio, com cálculos racionais bem precisos. Assim, enquanto o burocrata deixa passar sua vida pela rotina do cotidiano, o político abraça uma vida de percalços. Por isso, a recomendação bem explicita: "Quem for intimamente indefeso e incapaz de encontrar a devida resposta a si mesmo, fará melhor afastando-se dessa carreira” (WEBER, 1982, p. 138). Mas o burocrata não constitui um sujeito neutro, sua luta pelo poder desloca-se para um campo próprio. Por meios específicos, a tendência da burocracia moderna é aumentar cada vez mais seu poder. Mas, se o poder é o resultado de uma luta política, que meios estão à disposição da estrutura burocrática na luta pelo poder?

O processo de racionalização, como princípio estruturador da ordem social moderna, na sua dimensão tanto pública quanto privada, responde a essa questão pela capacidade técnica da burocracia racional ante outras formas de estruturas organizacionais. Mas Weber, no seu ensaio sobre a burocracia, quando analisa sua posição de poder, dá especial destaque para o segredo. Assim diz ele: "Toda burocracia busca aumentar a superioridade dos que são profissionalmente informados, mantendo secretos seus conhecimentos e intenções" (WEBER, 1982, p. 269). Weber vê nas chamadas "sessões secretas" uma espécie de abrigo onde

${ }^{5}$ Certamente Weber não desconhecia uma tradição ainda muito mais antiga conforme ele destaca em a Política como Vocação "Um maquiavelismo realmente radical, no sentido popular daquela palavra, está representado classicamente na literatura indiana, no Kautaliya Arthasastra (muito anterior a Cristo, supostamente da época de Chandragupta). Em contraste com esse documento, o Príncipe de Maquiavel é inofensivo" (WEBER, 1982, p. 148). 
a burocracia oculta o seu conhecimento e se protege da ação crítica.

A preocupação de Weber com o aumento de poder da burocracia é evidente, primeiramente, em "Parlamento e governo na Alemanha reconstruída", em que ele chama a atenção para o fato de que "o mais importante instrumento de poder do funcionalismo é a transformação da informação oficial em uma informação secreta, mediante o conceito mal-afamado do 'segredo oficial” (WEBER, 2014, p. 228-229, grifo no original).

Essa preocupação também está presente no ensaio sobre a burocracia: "o conceito do 'segredo oficial' é invenção específica da burocracia, e nada é tão fanaticamente definido pela burocracia quanto essa atitude que não pode ser substancialmente defendida além dessas áreas especificamente qualificadas" (WEBER, 1982, p. 270). Todas essas lições visaram o pathos político legado por Bismarck, em que a burocracia tende a sobrepor-se à política, e é aqui, nessa luta pelo protagonismo do poder na esfera do Estado, que Weber vê a possibilidade do resgate da dignidade da política; a "política deve ser o contrapeso à dominação do funcionalismo" (WEBER, 2014, p. 227).

No contexto geral do pensamento weberiano, existe uma preocupação em deixar evidente que a política, embora seja o elemento preponderante no processo civilizatório, é o lugar por excelência de profundas tensões sociais. Essas tensões alojam-se tanto nas lutas pelo desenvolvimento de um Estado-nação o que significa que os projetos políticos atravessam gerações, no sentido de uma "eterna luta" (WEBER, 2014, p. 22) -, quanto na constituição do comportamento ético ${ }^{6}$ do homem que tem a vocação para a política.

Daí o questionamento: "que tipo homem se deve ser para que se possa colocar a mão no leme da história?” (WEBER, 1982, p. 138). Assim, deixando evidente que abraçar a política por profissão não é uma decisão qualquer, assinala: "quem busca a salvação da alma, sua e dos outros, não deve buscá-la no caminho da política, pois as tarefas totalmente diferentes da política só podem ser resolvidas pela violência” (WEBER, 1982, p. 150).

Essas reflexões estabelecidas no pensamento político weberiano permitem-nos entender as preocupações com as ideias contidas em "O Estado-nação e a política econômica. Em primeiro lugar, a atenção de Weber volta-se para a ciência da política econômica, que, segundo ele, devia estar a serviço dos interesses políticos permanentes da nação, sobretudo quando se trata de "uma política de força" (WEBER, 2014, p. 22).

Em segundo lugar, esses interesses devem considerar que “o Estado-nação não é algo indefinido, que se torna mais sublime à medida que sua essência é encoberta por um manto de obscuridade mística, e sim a organização mundana do poder da nação" (WEBER, 2014, p. 22). Com essas afirmações, Weber parte para uma crítica contundente aos que se negam a ver que o poder, concentrado no Estado-nação, deve ser decisivo quanto à interferência na política econômica.

Assim, assinala: "Nesse Estado-nação, a 'razão de Estado' é para nós o último critério de valor para considerar também a política econômica” (WEBER, 2014, p. 22-23). A política é desenvolvida por meio de estratégias, sua atuação não é pacífica, depende de uma racionalidade instrumental baseada no cálculo preciso de meios e fins, mas, mesmo assim, não há como escapar da sua realidade, os objetivos políticos são quase sempre desafios-limite. Como disse Weber (1982, p. 153): “o homem não teria alcançado o possível se repetidas vezes não tivesse tentado o impossível".

O ponto culminante do pensamento weberiano em relação à política foi ter mostrado que a ação política trabalha num ambiente próprio da moralidade. A realpolitik não impõe desafios éticos somente a

\footnotetext{
${ }^{6}$ Não é objetivo deste texto esmiuçar os pormenores da discussão da ética da convicção e da ética da responsabilidade, que são parte da trágica situação do homem que escolhe a política como profissão. Indica-se a obra de Schluchter (2011), que faz uma profunda análise do conteúdo desses conceitos.
} 
quem se dispõe a manejar o leme da história, mas também a quem se dedica de forma apaixonada a estudar e a descortinar os seus mais recônditos meandros.

É sobretudo nesse âmbito que se pode referir a Carl Schmitt. Embora o universo jurídico-político construído por Schmitt não seja um terreno pacífico, dado a sua crítica profunda à democracia liberal, muito de seu suporte analítico deriva da obra de Weber. Críticos do pensamento antiliberal de Schmitt estão sempre apontando a relação intelectual entre esses dois autores.

Colliot-Thélène (1999, p. 138, tradução nossa) afirma: “Além de Hobbes e Hegel, Max Weber é um dos maiores interlocutores que Carl Schmitt escolheu para si mesmo; ele é um escritor de quem Schmitt emprestou argumentos e conceitos essenciais para seu próprio pensamento"7. Sobre as referências que aproximaram Schmitt de Weber. No que diz respeito à política, cabe afirmar que a obra de Schmitt pode ser encaixada no tema do advice-for-prince. Assim, se refere a ele Löwith (2006, p. 43): "Besides Hobbes and Hegel, Max Weber is one of the greatest of the interlocutors Carl Schmitt chose for himself; he is a writer from whom Schmitt borrowed arguments and concepts essential to his own thought".

O legado teórico e analítico de Carl Schmitt ${ }^{8}$, por sua busca incessante da precisão conceitual e por sua aguda relação com a realidade da política, quase sempre vista pelo olhar do jurista, constitui um "pensar a partir do extremo" (FERREIRA, 2004, p. 79). O objetivo principal de Schmitt é sem dúvida restabelecer, na sociedade moderna, o lugar do político, que havia sido deslocado do seu âmbito próprio - o Estado - para as estruturas que decidem em nome de outros elementos, como o mercado.

Pode-se confirmar tudo isso transcrevendo uma das suas afirmações mais importantes: "O conceito de Estado pressupõe o conceito do político” (SCHMIT'T, 1992, p. 43). Com isso somente nos resta acolher a afirmação de que "o Estado é o lugar por excelência do político, no pensamento de Schmitt e seu mundo é o mundo do Estado, além dele não há nada; ele concentra o monopólio da atividade política e sem este não existe atividade política” (SILVA, 2008, p. 450). É razoável dizer que, ao estabelecer essa condição para o Estado, Schmitt recoloca no cerne da política a ideia de soberania: "soberano é aquele que decide sobre o Estado de exceção" (SCHMITT, 1996, p. 89). E com isso a política se eleva à esfera da decisão.

Ao enfrentar essa questão, que é certamente o pilar principal do pensamento de Schmitt, constatase uma intensa busca para determinar os meandros da transformação dos conceitos teológicos em conceitos políticos secularizados". Assim diz Schmitt (1996, p. 109): "Todos os conceitos expressivos da moderna doutrina de Estado são conceitos teológicos secularizados”. Ao circunscrever a ideia de soberania na instância decisória da política ${ }^{10}$, Schmitt está evidenciando, de forma cabal, que as doutrinas políticas modernas

\footnotetext{
7 No original: "Besides Hobbes and Hegel, Max Weber is one of the greatest of the interlocutors Carl Schmitt chose for himself; he is a writer from whom Schmitt borrowed arguments and concepts essential to his own thought" (Colliot-Thélène, 1999, p. 138).

${ }^{8}$ Quase a totalidade dos trabalhos consultados acerca de Schmitt obrigatoriamente se reportam ao período de sua adesão ao nazismo. Especulam-se os argumentos que teriam levado a essa adesão um autor tão importante para se o pensamento jurídico político dos tempos modernos (BIGNOTTO, 2008; LESSA, 2003; LILLA, 2016; McCORMICK, 2004; MEIER, 1995; SCHWAB, 2004). Alguns acusam Schmitt de ser racista e antissemita; outros afirmam que ele era alguém que pretendia sobreviver ao sistema. "Esta actitud la explican diciendo que Schmitt, un hobbesiano, buscó la protección del soberano y por ello debió aceptar sus de designios" (SAMIR BENAVIDES, 2006, p. 127). Essa opinião parece estar em consonância com a afirmação: "Men, in Hobbes's vision, must submit their opinions to the rationality of Leviathan, without which they can have no proper, civilized existence" (QUILL, 2014).

9 Para um entendimento da discussão de Schmitt sobre a metafísica, ver Villas Bôas (2011).

10 Uma importante discussão sobre o decisionismo na política pode ser encontrada em Sá (2012).
} 
buscam enfraquecer e diluir por várias instâncias secundárias da política a soberania estatal herdada desde o Renascimento, situação que atinge seu ápice com o fim do absolutismo. A partir de então, impõe-se a democracia parlamentar.

A crítica fundamental de Schmitt à democracia parlamentar ${ }^{11}$, sob os princípios do liberalismo, é de que esta institui uma ordem social que se distingue pelo autogoverno ou mesmo por uma autorregulação. Essa ordem jurídico-política, que nega ao Estado o efetivo preceito do decisionismo, somente é capaz de lidar com a normalidade jurídica, deixando ao largo a excepcionalidade. Para Schmitt, no caso excepcional, o Estado suspende o direito para garantir sua autoconservação. Nesse sentido, uma perturbação da normalidade, uma ruptura profunda da ordem faz com que o Estado, mesmo sob o sacrifício do direito, permaneça, e com ele permanece o último elemento da ordem, que certamente não é jurídica, mas estritamente política (SÁ, 2012, p. 62).

Nos pressupostos críticos de Schmitt, sobretudo no princípio da crença na opinião pública, na publicidade, que é um dos pilares do sistema democrático parlamentar atual, está a arma desse sistema contra a raz̧ão de Estado e consequentemente contra o segredo de Estado ${ }^{12}$. A contraposição democrática parlamentar tem sua base numa literatura antimaquiaveliana, que se contrapõe, diz Schmitt (1996, p. 36), à

[...] teoria dos segredos de Estado, a Arcana rei publicae, que predominava em inúmeros escritos dos séculos XVI e XVII. Essa teoria [...] começa com a literatura da razão de Estado, a ratio status, da qual ela é, na verdade, a própria essência.

O foco principal da literatura antimaquiaveliana é antes de tudo converter a razão de Estado numa técnica de manutenção e de expansão do poder, reservada para a ação política de monarquistas e absolutistas. Assim, a crítica vai assentar-se no argumento segundo o qual, "ao ideal do poder de uma técnica política, contrapõem-se os conceitos de direito e de justiça". Isso seria o desenrolar de "antiga luta entre poder e direito" em que "a técnica maquiavélica do poder é combatida com um ethos moral e político" (SCHMITT, 1996, p. 37).

No texto de Schmitt, encontra-se uma descrição do sistema parlamentar com seus níveis organizacionais enquadrando o sistema de deliberação parlamentar (aqui a ideia de "deliberação" contrasta com a ideia de "decisão"). Assim, "o Parlamento é uma comissão do povo, o governo é uma comissão do Parlamento", embora isso constitua o essencial da democracia, Schmitt diz que "não o é", pois, na sua interpretação da situação parlamentar, se, "por motivos técnicos, pessoas confiáveis do povo tomam decisões no lugar do povo, também é possível que uma única pessoa de confiança tome decisões em nome desse mesmo povo" (SCHMITT, 1996, p. 34). A crítica mais contundente de Schmitt à democracia repousa, em primeiro lugar, no fato de que a técnica de condução da política pelo Parlamento desconfigura a relação entre eleitor e deputado. Em segundo lugar, denuncia Schmitt (1996, p. 21)

[...] as decisões importantes são tomadas sempre em reuniões secretas de dirigentes de facções ou até

${ }^{11}$ É bastante interessante como Schmitt tem chamado a atenção de autores que Mouffe (1999) classifica como "identified with the left" e que buscam responder questões do tipo: "Why should we read Carl Schmitt today? [...] Do liberal democrats have something to learn from his critique of liberalism?". Em um outro trabalho, Mouffe (2005, p. 2) afirma: "Schmitt's critique of liberal democracy constitutes, in my view, a challenge that we cannot ignore".

12 Essa discussão é abordada sobretudo no capítulo dois do seu livro Die geistesgeschichtliche Lage des heutigen Parlamentarismus (A situação intelectual do sistema parlamentar). 
mesmo nos comitês extraparlamentares, dando margem a desvios e isenções de responsabilidades, transformando o sistema parlamentar numa péssima fachada para o poderio dos partidos e dos interesses econômicos.

Prosseguindo com essa crítica, diz Schmitt (1996, p. 48)

[...] comissões cada vez mais restritas de partidos e de coalizões partidárias tomam decisões a portas fechadas, e aquilo que os representantes dos grandes interesses capitalistas decidem em comitês fechados é talvez mais importante do que quaisquer decisões políticas, para o dia-a-dia e o destino de milhões de pessoas.

Schmitt destaca que a democracia parlamentar liberal, na sua luta contra o absolutismo e, consequentemente, contra a ratio status, concebe o poder da opinião pública e do equilíbrio entre a divisão de poderes como os instrumentos mais eficazes para aproximar as demandas da sociedade das decisões políticas. É o discurso da transparência na ação política do Parlamento contra a "confidential language used in memoranda and letters, or whispered in de prince's ears, or discussed in the secret the prince's room”. (VIROLI, 1992, p. 252), ou contra aquilo que Weber (2014, p. 229) denominou "mal-afamado segredo oficial".

No entanto, como a política praticada nos parlamentos modernos aderiu às câmaras secretas do poder, em que a opinião pública é substituída pela publicidade da opinião, Schmitt (1996, p. 48) conclui: "como são inofensivos e idílicos os objetos daquela política de gabinete dos séculos XVII e XVIII, ao lado dos destinos que são atualmente objeto de negociações e de todo tipo de segredo”.

\section{O SEGREDO DE ESTADO E A AMEAÇA À DEMOCRACIA}

A democracia impõe-se por trazer a política de volta à esfera pública. Arendt (2011, p. 133) vê de forma positiva o esforço da revolução americana para conceber uma república que se estruturou politicamente com base no princípio democrático do pluralismo de ideias. As práticas democráticas na modernidade valeram-se de instrumentos da teoria política e do discurso das liberdades política e econômica para minar e derrotar um tipo de Estado que serviu de moldura ao poder absoluto. Como se vê pelas notas de Schmitt, em lugar do decisionismo ou deliberacionismo ${ }^{13}$ democrático legitimamente discutido na esfera própria da política, as eleições e os parlamentos.

No entanto, até que ponto esse processo histórico, de certo modo singular no mundo ocidental, reconstituiu a esfera pública de participação do cidadão, ou a instituição da representação delimitou o sujeito político sob o princípio da heteronomia, revertendo assim sua vontade em interesses coorporativos? A suspeita de que a democracia representativa não tem tido a força específica para restringir o domínio dos meios de ocupação do poder pode ser observada a partir de uma análise da ação política sob a visão das noções de razão de Estado e de segredo.

O Estado e sua gestão democrática, no cerne da política moderna, constituem a arena principal da tensão entre publicidade e segredo. Neocleous (2003) deixa evidente que um segredo mantido por governos, quando revelado, expõe também que a justificativa de tal prática se ampara no discurso e na lógica da rąão de Estado.

Para provar isso, Neocleous (2003) vale-se de uma declaração de Donald Rumsfeld, então secretário

${ }^{13}$ A ideia de deliberação certamente tem suas origens na denominada Escola de Frankfurt, sendo Habermas (2008) o seu mais importante teórico. 
de defesa dos Estados Unidos: primeiro, ele afirmou que os prisioneiros de Guantánamo não estavam amparados pela convenção de Genebra; segundo, "he also 'made it clear that raison d'État would determine the US government's approach to this question"” (NEOCLEOUS, 2003, p. 40). Esse caso, que, no todo, é somente uma evidência de que o Estado liberal, com seus princípios fundamentais apoiados no Estado de direito, manteve latente os velhos meios da arcana imperii (os mistérios do governo), é a forma de instrumentalizar a máxima dos fins justificam os meios.

Não há como fugir de aventar que a ação política, no âmbito sobretudo da segurança da sociedade, incorpora-se à capacidade que os governos democráticos têm de manipular as informações. Arendt ${ }^{14}$ vê essas manipulações como fazendo parte da ação e da imaginação política. Assim, por exemplo, ela diz: "Sigilo [...] e embuste, ou seja, a falsidade deliberada e a mentira descarada, são usadas como meios legítimos para alcançar fins políticos desde os primórdios da história documentada” (ARENDT, 2008, p. 14).

E mais adiante: "a negação deliberada da verdade dos fatos - isto é, a capacidade de mentir - e a faculdade de mudar os fatos - a capacidade de agir - estão interligadas; devem sua existência à mesma fonte: imaginação" (ARENDT, 2008, p. 15). Nesse quadro, os instrumentos da democracia parecem cada vez mais limitados ou mesmo autolimitados diante da ideia de segurança.

Nesse campo, o Estado de direito fica à sombra da violência usada como meio racional incorporado ao Estado; é como se por detrás do discurso da liberdade individual permanecesse latente a máxima salus rei publicae suprema lex. Com isso, a consolidação do poder depende da disponibilização de informações não apenas sobre as movimentações para além das fronteiras do Estado-nação, mas principalmente sobre os próprios cidadãos. Segundo Quill, isso justifica um importante esforço para distinguir as esferas da ética e da política e para justificar que "an action considered immoral in private life might be sanctioned and defended if taken in interest of state" (QUILL, 2014, p. 67).

Em um trabalho sobre o episódio do WikiLeaks (tal qual Arendt sobre os Pentagon Papers), Quill mostra como no século XX cresceram as redes de informações de que dispõem os governos e a mistura de burocracia e networks foi responsável por uma expansão do segredo, trazendo uma nova dinâmica para a tradicional autoridade burocrática. $\mathrm{Na}$ análise de Quill, "a reliance upon technology to accelerate the processing of information, and the mutually reinforcing nature of foreign and domestic policy agendas have served to undermine the idea at the heart of liberal democratic theory: that the individual is sovereign" (QUILL, 2014, p. 92).

Assim, para esse autor, "WikiLeaks could, therefore, be perceived as an integral part of the functioning of liberal democracies" (QUILL, 2014, p. 124), pois os vazamentos seriam um caminho para manter o direito de uma cidadania esclarecida. Por outro lado, isso viria expor, nas palavras de Quill, o quanto a "Hypocrisy is a central feature of life in liberal democracies, one that is necessary and part of the integral functioning of the political system” (QUILL, 2014, p. 145).

Em geral, quando se analisa o desenrolar da política democrática na modernidade, suspeita-se de que sempre há algo sigiloso, oculto, em segredo por trás das ações políticas governamentais, o que converte a política numa arte de manipular todos os elementos de que dispõe. Sabe-se que esses instrumentos determinam o vigor ou a fragilidade de uma estrutura democrática. Essa avaliação confirma a afirmação de Neocleous (2003, p. 62) que: "the higher the degree of secrecy the state operates with, the less democratic it is". Seguindo argumento semelhante, Quill assinala

${ }^{14}$ O texto de Hannah Arendt (2008) trata especificamente do episódio conhecido como Pentagon Papers em que foram divulgados documentos sobre a guerra do Vietnã. 
Arguably, the biggest secret to emerge from the WikiLeaks phenomenon was the secret about liberal democracies - that in societies that pride themselves on openness, transparency, and freedom of speech, there are some things that simply will not be talked about (QUILL, 2014, p. 148).

A exposição destes, e provavelmente de vários outros, fatos da história contemporânea, mostram os riscos e os perigos que rondam as democracias e seus ideais.

\section{CONSIDERAÇÕES FINAIS}

Os aparatos burocráticos do Estado moderno, com crescente emprego de tecnologia de comunicação, tornaram de certa forma idílicos os aparatos de informação que serviram os príncipes, séculos atrás, na arte de governar. Como corolário imediato da relação entre burocracia e network, veio o estabelecimento do dilema da segurança na sociedade democrática. Se a cultura política ocidental foi capaz de difundir os valores da liberdade, não teve a mesma força para tirar de cena a prática da vilania, da mentira e da violência na ação política.

Talvez, por esse motivo, continuaram, no cerne dos regimes democráticos, à disposição das narrativas autoritárias, as noções de razão de Estado e segredo. É possível depreender das lições dadas pelos autores estudados, que essas ideias ao longo do tempo permaneceram, evoluíram e até se tornaram mais adequadas para justificar os dilemas da democracia, entre os quais aquele de que a segurança é o limite da liberdade e da privacidade.

O século XX, com suas duas guerras mundiais e a guerra fria, que ameaçaram aniquilar a humanidade, foi pródigo na sofisticação da ocultação e do segredo nas relações políticas. Na falta de outro arsenal teórico, só restou ao estudo da política retornar às lições dos mestres do realismo - Maquiavel, Weber e Schmitt -, que persistiram em mostrar a política como ela é, não como deveria ser. Assim, o confronto com o arcabouço analítico da teoria democrática revelou as ambivalências das atitudes de diversos governos e governantes constituídos com base nos princípios da liberdade e do Estado de direito.

A questão seria em que medida esses expedientes são mobilizados para proteger a sociedade e o indivíduo e em que medida eles são meios ilegítimos que apenas permitem elevar o poder dos governos e dos grupos políticos estabelecidos. Assim, até que nível essa política pode elevar os riscos para a democracia? Um panorama conclusivo do dilema da democracia - ante o medo e a incerteza, que ganharam status de prática civilizatória e, desde Thomas Hobbes, têm reafirmado a sua presença - pode ser encontrado na assombrosa afirmação: "Os esplendores da liberdade estão em seu ponto mais brilhante quando a liberdade é sacrificada no altar da segurança” (BAUMAN, 1998, p. 10).

\section{REFERÊNCIAS}

ÁGUILA TEJERINA, Rafael del. La senda del mal: política y razón de Estado. Madrid: Taurus, 2000. ARENDT, Hannah. A mentira na política: considerações sobre os documentos do Pentágono. In: ARENDT, Hannah. Crises da República. São Paulo: Perspectiva, 2008.

, Hannah. Sobre a Revolução. São Paulo: Companhia das Letras, 2011.

BAUMAN, Zigmunt. O mal-estar da pós-modernidade. Rio de Janeiro: Zahhar, 1998. 
BERLIN, I. Against the current: essays in the history of ideas. Isaiah Berlin. Selected writings, v. 3, 1980.

BIGNOTTO, Newton. As Fronteiras da Ética: Maquiavel. In: NOVAES, Adalto. Ética. São Paulo: Companhia das Letras, 1992.

, Newton. Soberania e exceção no pensamento de Carl Schmitt. Kriterion: Revista de Filosofia, Belo Horizonte, v. 49, n. 118, p. 401-415, dez. 2008.

BÔAS, Pedro Villas. A despolitização da democracia liberal no pensamento de Carl Schmitt. Revista Brasileira de Ciências Sociais, v. 26, n. 77, p. 113-128, 2011.

CANETTI, Elias. Massa e Poder. São Paulo: Companhia das Letras, 1995.

COLLIOT-THÉLÈNE, Catherine. Carl Schmitt versus Max Weber: juridical rationality and economic rationality. In: MOUFFE, Chantal (Ed.). The challenge of Carl Schmitt. London: Verso, 1999. p. 138154.

CROCE, Benedetto. Etica e politica. Milano: Adelphi, 1994.

CURZIO, Leonardo. La forja de un concepto: la razón de Estado. Estudios Políticos, n. 2, p. 27-72, mayo/agosto 2004.

DREIFUSS, René. Política, poder, Estado e força: uma leitura de Weber. Petrópolis, RJ: Vozes, 1993.

FERNÁNDEZ RAMOS, José Carlos. Hobbes, Gracián, y la razón de Estado. Intersticios: Revista Sociológica de Pensamiento Crítico, v. 6, n. 2, p. 309-321, 2012.

FERREIRA, Bernardo. O risco do político: crítica ao liberalismo e teoria política no pensamento de Carl Schmitt. Belo Horizonte: UFMG, 2004.

GREENWALD, Glenn. Sem lugar para se esconder: Edward Snowden, a NSA e a espionagem do governo americano. Rio de Janeiro: Sextante, 2014.

HABERMAS, Jürgen. Teoría de la acción comunicativa. Madrid: Taurus, 2008 [1981]. 2 v.

LESSA, Renato. A política como ela é...: Carl Schmitt e o realismo político como agonia e aposta. In: LESSA, Renato. Agonia, aposta e ceticismo: ensaios de filosofia política. Belo Horizonte: UFMG, 2003. p. 15-54.

LILLA, Mark. The reckless mind: intellectuals in politics. New York: New York Review of Books, 2016.

LÖWITH, Karl. El decisionismo ocasional de Carl Schmitt. In: LÖWITH, Karl. Heidegger, pensador de un tiempo indigente: sobre la posición de la filosofía en el siglo XX. Buenos Aires: Fondo de Cultura Económica, 2006. p. 43-86.

MAQUIAVEL, Nicolau. O príncipe: escritos políticos. São Paulo: Abril Cultural, 1983. (Coleção Os Pensadores).

MAYER, Jacob Peter. Max Weber and German politics: 1890-1920. London: Psychology Press, 1998.

McCORMICK, John. Introdution. In: SCHMITT, Carl. Legality and Legitimacy SCHMITT, Carl. Legality and legitimacy. Duke University Press, 2004.

MEIER, Heinrich. Carl Schmitt and Leo Strauss: the hidden dialogue. Chicago: University of Chicago Press, 1995.

MOUFFE, Chantal. The challenge of Carl Schmitt. London: Verso, 1999. 
, Chantal. The return of the political. London: Verso, 2005.

NEOCLEOUS, Mark. Imagining the state. Maidenhead (UK): McGraw-Hill Education, 2003.

QUILL, Lawrence. Secrets and Democracy: from arcana imperii to Wikileaks. Springer, 2014.

SÁ, Alexandre Franco de. Poder, direito e ordem: ensaios sobre Carl Schmitt. Rio de Janeiro: Via Verita, 2012.

SAMIR BENAVIDES, Farid. Excepción, decisión y derecho en Carl Schmitt. Argumentos, México, DF, v. 19, n. 52, p. 125-145, sept./dic. 2006.

SCHLUCHTER, Wolfgang. Paradoxos da modernidade: cultura e conduta na teoria de Max Weber. São Paulo: Unesp, 2011.

SCHMITT, Carl. A crise da democracia parlamentar. São Paulo: Scritta, 1996.

, Carl. 0 conceito do político. Petrópolis, RJ: Vozes, 1992.

SCHWAB, George. Introduction. In: SCHMITT, Carl. The concept of the political. Chicago: University of Chicago Press, 2004. p. 3-16.

SILVA, Washington Luiz. Carl Schmitt e o conceito limite do político. Kriterion: Revista de Filosofia, Belo Horizonte, v. 49, n. 118, p. 449-455, dez. 2008.

SIMMEL, Georg. The sociology of secrecy and of secret societies. The American Journal of Sociology, v. 11, n. 4, p. 441-498, Jan. 1996.

SKINNER, Quentin. As fundações do pensamento político moderno. São Paulo: Companhia das Letras, 1996.

STRAUSS, Leo. Thoughts on Machiavelli. Chigago: The University of Chicago Press, 1958.

VELÁZQUEZ DELGADO, Jorge. Antimaquiavelismo y razón de Estado: ensayos de Filosofía Política del Barroco. Signos Filosóficos, v. 15, n. 29, p. 225-229, enero/junio 2013.

VIROLI, Maurizio. From Politics to Reason of State: The Acquisition and Transformation of the Language of Politics 1250-1600. Cambridge University Press, 1992.

WEBER, Max. Ensaios de Sociologia. 5. ed. Rio de Janeiro: Guanabara, 1982.

, Max. Escritos políticos. São Paulo: WMF Martins Fontes, 2014. 